\title{
Peran Optimisme dan Dukungan Sosial terhadap Integritas Ego pada Lanjut Usia
}

\section{Alfi Purnamasari, Ismira Dewi}

Program Studi Psikologi, Fakultas Psikologi, Universitas Ahmad Dahlan, Yogyakarta

Abtrak. Pada usia lanjut, individu mengalami perubahan pada seluruh aspek perkembangan. Salah satu yang berpengaruh pada perkembangan psikososial lanjut usia adalah integritas ego. Penelitian ini bertujuan untuk mengetahui hubungan antara dukungan sosial dan optimisme terhadap integritas ego pada lanjut usia. Subjek penelitian sebanyak 61 orang yang berusia lebih dari 60 tahun dan berdomisili di kota Yogyakarta. Teknik pengambilan sampel yang digunakan dalam penelitian ini adalah menggunakan metode purposive sampling. Instrumen penelitian yang digunakan adalah skala Optimisme, skala Dukungan Sosial, dan skala Integritas Ego. Analisis data menggunakan teknik analisis regresi. Hasil penelitian menunjukkan bahwa optimisme dan dukungan sosial secara bersama-sama akan memengaruhi integritas ego pada lansia, optimisme juga memiliki pengaruh yang positif terhadap integritas ego, namun dukungan sosial tidak memberikan dampak apapun terhadap integritas ego apabila tidak disertai dengan optimisme yang tinggi.

Kata Kunci: dukungan sosial, integritas ego, lansia, optimisme

\section{The Role of Optimism and Social Support in Ego Integrity among Elderly}

Abstract. In elderly phase, individuals experience changes in all aspects of development that affect psychosocial development, one of them is ego integrity. The study aims to determine the relationship between social support and optimism on ego integrity among elderly. The subjects were 61 people over 60 years old lives in Yogyakarta. The sampling technique used in this study was purposive sampling. The instruments used were Optimism scale, Social Support scale, and Ego Integrity scale. The data analysis technique used was regression analysis techniques. The result showed that optimism and social support together will affect ego integrity of the elderly, optimism also has a positive influence on ego integrity, but social support will not have any impact on ego integrity if it is not balanced with high optimism.

Keywords: ego integrity, elderly people, optimism, social support

Korespondensi: Alfi Purnamasari. Email: alfi.purnamasari@psy.uad.ac.id 
Lanjut usia atau yang biasa dikenal dengan istilah lansia merupakan suatu fase kehidupan terakhir dalam proses perkembangan manusia. Menurut Peraturan Pemerintah Republik Indonesia Nomor 34 Tahun 2004, lanjut usia adalah seseorang yang berusia 60 tahun ke atas. Data proyeksi penduduk memperkirakan jumlah penduduk lansia di Indonesia tahun 2020 akan berjumlah 27,08 juta, sehingga Indonesia termasuk negara dengan struktur penduduk menuju tua karena mempunyai populasi lansia di atas tujuh persen. Menurut Kementerian Kesehatan RI (2017) yang berkaitan dengan situasi lanjut usia di Indonesia, diperoleh data bahwa jumlah lansia di Provinsi Daerah Istimewa Yogyakarta (DIY) menempati urutan kelima dari seluruh provinsi yang ada di Indonesia. Pemerintah mencanangkan tanggal 29 Mei sebagai Hari Lanjut Usia Nasional (HLUN) sebagai momen untuk meningkatkan kesadaran/perhatian masyarakat terhadap kesejahteraan lansia. Alasan penelitian ini dilakukan di kota Yogyakarta adalah karena jumlah penduduk lansia di kota Yogyakarta mencapai 13\% dari jumlah penduduk kota Yogyakarta secara keseluruhan, yakni 45,000 orang.

Masalah yang berkaitan dengan kelompok lanjut usia di kota Yogyakarta mengalami peningkatan. Permasalahan yang muncul pada lansia adalah kurangnya apresiasi, sehingga tidak jarang para lansia terlantar meskipun mereka memiliki keluarga. Selain itu, permasalahan lain yang muncul adalah proses penuaan yang mengakibatkan lansia mengalami penurunan kemampuan fisik dan kognitif, kemampuan panca indera terhadap daya tangkap visual, memori, kepekaan pendengaran, dan ketajaman penciuman menurun secara gradual. Lansia juga banyak yang mengalami penyakit pada berbagai organ. Kombinasi perubahan alamiah dan penyakit yang dialami membuat lansia merupakan populasi manusia yang rentan apabila tidak diperhatikan (Surat Keputusan Walikota Yogyakarta Nomor 450 Tahun 2019 Tentang Roadmap Kota Yogyakarta Menuju Kota Ramah Lanjut Usia, 2019).

Menurut Haley et al. (2016), individu yang memasuki usia lanjut akan mengalami beberapa perubahan, antara lain: (a) perubahan fisik dan mobilitas, (b) kualitas hidup, serta (c) peran di lingkungan sosial. Besarnya jumlah penduduk lansia akan membawa dampak positif apabila lansia berada dalam keadaan sehat, baik secara fisik dan psikis, aktif, dan produktif. Di sisi lain, dampak negatif juga akan muncul jika lansia memiliki masalah penurunan kesehatan, peningkatan disabilitas, serta tidak adanya dukungan sosial dan lingkungan yang ramah terhadap penduduk lansia.

$$
\text { Perkembangan psikososial }
$$
menunjukkan bahwa orang lanjut usia akan mengalami konflik psikologis terakhir yang menurut Erikson (Berk, 2012; Westerhof et al, 2015) disebut dengan integritas ego versus putus asa (ego integrity versus despair) yang melibatkan perasaan seseorang untuk dapat 
berdamai dengan hidup. orang lanjut usia yang memiliki perasaan integritas akan merasa utuh dan puas dengan pencapaian yang telah diperoleh selama ini. Perasaan putus asa akan muncul apabila orang lanjut usia merasa tidak memiliki cukup waktu untuk menemukan cara meraih integritas. Haber (2006) menyampaikan bahwa integritas ego diidentifikasikan sebagai komponen penting dari kepuasan hidup. Perempuan memiliki tingkat integritas ego yang lebih tinggi dan kesejahteraan secara menyeluruh, serta lebih mampu menyelesaikan penyesalan dalam kehidupan mereka (Torges et al., 2009). Menurut Erikson (1998), integritas ego merupakan kemampuan untuk melihat kehidupan diri sendiri dalam konteks manusia yang lebih luas sebagai gabungan dari kesempatan menjadi pribadi dan bagian dari sejarah yang seluruhnya berperan penting bagi ketenangan dan kepuasan yang mengiringi integritas (Berk, 2017).

Menurut Peck (1968), integritas ego meliputi aspek (a) diferensiasi ego (ego differentiation), (b) transendensi tubuh (body transcendence), dan (c) transendensi ego (ego transcendence). Differensiasi ego berkaitan dengan mencari cara-cara untuk menegaskan harga diri melalui keluarga, persahabatan, dan kehidupan komunitas. Transendensi tubuh berkaitan dengan kemampuan untuk mengatasi keterbatasan fisik dengan mengerahkan sumber daya kognitif, emosional, dan sosial. Transendensi ego muncul dalam bentuk usaha untuk menghadapi kematian dengan konstruktif melalui upaya untuk menjadikan hidup lebih aman, bermakna, dan bahagia bagi generasi muda. Hasil penelitian yang dilakukan oleh Peck (1956) menunjukkan bahwa seiring bertambahnya usia lansia, maka baik transendensi tubuh (orientasi pada kekuatan psikologis) dan transendensi ego (orientasi pada masa depan) juga akan meningkat. Penelitian yang dilakukan oleh Peck (Peck, 1956) terhadap wanita lanjut usia menunjukkan bahwa wanita lanjut usia yang berusia 80 dan 90 akan merasa lebih yakin daripada wanita lanjut usia yang berusia enam puluhan bahwa mereka mampu menerima perubahan akibat penuaan, mampu mengatasi ketakutan akan kematian, memiliki pemahaman yang lebih jelas akan arti kehidupan, menemukan gairah batin baru, dan positif untuk melakukan eksplorasi.

Penelitian menunjukkan bahwa optimisme adalah prediktor kuat pada kesejahteraan lanjut usia serta memiliki kontribusi terhadap kesejahteraan lansia (Ferguson \& Goodwin, 2010) maupun pencapaian kesuksesan di masa tua (Dumitrache et al., 2019). Selain itu, secara umum, optimisme akan memberikan dampak positif pada proses penuaan secara sehat (James et al., 2019). Berdasarkan hasil studi sebelumnya, optimisme pada lansia dirumuskan sebagai (a) kesiapan untuk mengapresiasi beragam hal dalam hidup, (b) berpikiran positif dan merasa puas, serta (c) adanya determinasi dan harapan (Menezes \& Thomas, 2018). Dinamikanya adalah ketika lansia memiliki 
optimisme, maka hal tersebut akan membantunya dalam mengatasi berbagai perubahan dalam hidupnya. Dengan demikian, lansia akan mampu mengintegrasikan masa lalu, mengembangkan kepuasan hidup di masa kini, serta menghadapi kematian di masa depan. Hal ini senada dengan kajian dari Carver et al. (Carver et al, 2010) yang menyatakan bahwa optimisme akan membantu individu untuk mengembangkan koping positif walaupun tengah dalam kesulitan atau tantangan.

Selain itu, penurunan fungsi di segala aspek perkembangan memberikan dampak bahwa lansia harus mendapat prioritas utama dalam penanganannya agar tetap dapat menjalankan fungsi serta kebutuhan jasmani dan rohaninya agar tetap terpenuhi. Maka dari itu, lanjut usia sangat memerlukan dukungan sosial dalam kehidupannya. Tinjauan dari beberapa literatur membuktikan bahwa kontribusi dukungan sosial sebagai prediktor pada integritas ego (Au et al., 2009; Khusaifan \& El Keshky, 2017; Liu \& Huang, 2018; Yeung \& Fung, 2007). Hal ini diperkuat pula dengan hasil riset yang menunjukkan bahwa relasi interpersonal yang harmonis dengan orang lain akan menyokong integritas ego pada diri lansia (Jeong \& Oh, 2015; Lim \& Chang, 2018). Hasil penelitian yang dilakukan oleh Tahreen dan Shaded (2014) dengan subjek 50 orang wanita berusia di atas 50 tahun dan 50 pria berusia di atas 50 tahun menunjukkan bahwa dukungan sosial dapat meningkatkan integritas ego dan kesehatan mental. Dengan demikian, dukungan sosial memiliki peran penting dalam pengembangan integritas ego.

Dukungan sosial dapat diartikan sebagai proses interpersonal yang berfungsi untuk mendorong upaya individu dalam pertumbuhan diri maupun adaptasi di situasi sulit (Feeney \& Collins, 2015). Dukungan sosial di masa lansia sangat diperlukan, sebab dapat memberikan pengaruh pada kualitas hidup lansia secara umum, baik dari sisi kesehatan fisik maupun psikologis (Chang et al., 2014; Unsar et al., 2016). Dukungan sosial yang ditunjang dengan aktivitas rekreasi bagi lansia akan berdampak positif pada kualitas kesehatannya (Chang et al, 2014). Hal ini berkaitan pula dengan integritas ego sebagai indikator perkembangan lansia yang sehat secara psikologis. Dukungan sosial dari keluarga diperlukan oleh lansia, karena lansia membutuhkan pemeliharaan dan interaksi dengan generasi berikutnya, serta kerabat lain di luar keluarga untuk menjaga eksistensi dirinya. Hal ini selayaknya terjadi karena keluarga merupakan sumber dukungan sosial yang alami. Selain itu, dukungan keluarga juga menyumbang peranan penting, sebab lansia rentan berhadapan dengan kehilangan pasangan maupun teman sebaya karena kematian (Waite \& Das, 2010). Menurut Berk (Berk, 2017), selama konteks sosial dan budaya memberikan lansia dukungan, penghargaan, dan arah hidup, maka masa usia lanjut dapat menjadi masa keberlanjutan potensi pada lansia. Dengan demikian, dinamika dukungan sosial pada pembentukan integritas ego sangat diperlukan. 
Mengingat pentingnya integritas ego bagi lansia, maka peneliti tertarik untuk melakukan penelitian untuk melihat hubungan antara optimisme dan dukungan sosial terhadap integritas ego. Hipotesis yang diajukan dalam penelitian ini adalah sebagai berikut:

1. Hipotesis mayor: Ada hubungan antara optimisme dan dukungan sosial dengan integritas ego pada lansia.

2. Hipotesis minor:

a. Ada hubungan positif antara optimisme dan integritas ego pada lansia. Semakin tinggi optimisme maka akan semakin tinggi integritas ego pada lansia dan sebaliknya, semakin rendah optimisme maka akan semakin rendah integritas ego pada lansia;

b. Ada hubungan positif antara dukungan sosial dan integritas ego pada lansia. Semakin tinggi optimisme maka akan semakin tinggi integritas ego pada lansia dan sebaliknya, semakin rendah optimisme maka akan semakin rendah integritas ego pada lansia.

\section{Metode}

\section{Uji coba alat ukur}

Pengumpulan data menggunakan skala Optimisme, skala Dukungan Sosial, dan skala Integritas Ego yang disusun oleh peneliti. Skala Optimisme digunakan untuk mengukur tingkat optimisme dan disusun berdasarkan aspekaspek optimisme yang dikemukakan oleh Seligman (2006) yang terdiri dari: (a) keabadian (permanence), (b) peresapan (pervasiveness), dan (c) personalisasi (personalization). Skala Dukungan Sosial digunakan untuk mengukur tingkat dukungan sosial yang diterima. Skala dukungan sosial disusun berdasarkan aspek-aspek dukungan sosial yang dikemukakan oleh Sarafino dan Smith (2011) yang terdiri dari: (a) dukungan emosi, (b) dukungan penghargaan, (c) dukungan informasi, dan (d) dukungan instrumen. Skala Integritas Ego digunakan untuk mengukur tingkat integritas ego dan disusun berdasarkan aspek-aspek integritas ego yang dikemukakan oleh Peck (1968) yang meliputi: (a) diferensiasi ego, (b) transendensi tubuh, dan (c) transendensi ego.

Skala menggunakan model summated rating scale dengan empat alternatif jawaban, yaitu: Sangat Sesuai (SS), Sesuai (S), Tidak Sesuai (TS), dan Sangat Tidak Sesuai (STS). Kriteria pemberian skor untuk butir-butir favorabel pada jawaban Sangat Sesuai (SS) mendapat skor 4, jawaban Sesuai (S) mendapat skor 3, jawaban Tidak Sesuai (TS) mendapat skor 2 dan jawaban Sangat Tidak Sesuai (STS) mendapat skor 1 . Kriteria pemberian skor untuk butir-butir unfavorabel yakni jika jawaban Sangat Sesuai (SS) mendapat skor 1, jawaban Sesuai (S) mendapat skor 2, jawaban Tidak Sesuai (TS) mendapatskor 3, dan jawaban Sangat Tidak Sesuai (STS) mendapat skor 4.

Sebelum digunakan dalam penelitian, terlebih dahulu dilakukan uji coba alat ukur terhadap skala Optimisme, skala Dukungan 
Sosial dan skala Integritas Ego kepada 50 orang lanjut usia yang memiliki karakteristik yang sama dengan subjek penelitian, yaitu berusia 60 tahun ke atas yang tinggal di kota Yogyakarta, serta memiliki kemampuan penglihatan dan pendengaran yang masih baik. Hasil analisis butir dari ketiga skala tersebut dapat dilihat pada Tabel 1 .

\section{Tabel 1}

Hasil Analisis Butir Skala Optimisme, Skala Dukungan Sosial, dan Skala Integritas Ego

\begin{tabular}{lcccc}
\hline \multicolumn{1}{c}{ Skala } & Jumlah Butir & $\begin{array}{c}\text { Indeks Daya } \\
\text { Beda Butir } \\
\text { Terendah }\end{array}$ & $\begin{array}{c}\text { Indeks Daya } \\
\text { Beda Butir } \\
\text { Tertinggi }\end{array}$ & $\alpha$ \\
\hline Optimisme & 24 & .330 & .774 & .897 \\
Dukungan sosial & 24 & .301 & .696 & .920 \\
Integritas ego & 18 & .241 & .793 & .903 \\
\hline
\end{tabular}

\section{Prosedur penelitian}

Pengambilan data penelitian dilakukan terhadap 61 orang lanjut usia yang berusia 60 tahun ke atas yang tinggal di kota Yogyakarta dan memiliki kemampuan penglihatan dan pendengaran yang masih baik sehingga mampu membaca skala dan memberikan respon secara mandiri. Sampel penelitian dipilih menggunakan purposive sampling dengan cara menemui lansia yang menjadi peserta dalam kegiatan Pos Pelayanan Terpadu (Posyandu) lansia di kota Yogyakarta. Sebagian besar lansia berjenis kelamin perempuan dan memiliki tingkat pendidikan Sekolah Menengah Atas (SMA). Sebelum proses pengambilan data penelitian, peneliti menyampaikan terlebih dahulu maksud dan tujuan dilakukannya pengambilan data, sehingga subjek lansia memahami dan dapat menyatakan kesediaannya untuk terlibat sebagai subjek penelitian. Para lansia kemudian mengisi ketiga skala yang diberikan, yaitu skala Optimisme, skala Dukungan Sosial, dan skala Integritas Ego.

\section{Hasil}

\section{Analisis data}

Teknik analisis data yang digunakan dalam penelitian adalah analisis regresi berganda. Sebelum dilakukan analisis dengan menggunakan analisis regresi berganda, terlebih dahulu dilakukan uji asumsi yang meliputi uji normalitas, uji linieritas, dan uji multikolinieritas.

\section{Deskripsi data penelitian}

Kategorisasi data penelitian dibuat berdasarkan skor hipotetik dan dapat dilihat pada Tabel 2 berikut. 
Tabel 2

Kategorisasi Optimisme, Dukungan Sosial, dan Integritas Ego

\begin{tabular}{lccc}
\hline \multicolumn{1}{c}{ Kategori } & Optimisme & Dukungan Sosial & Integritas Ego \\
\hline Tinggi & $57.37 \%$ & $1.64 \%$ & $100 \%$ \\
Sedang & $42.63 \%$ & $93.44 \%$ & 0 \\
Rendah & $0 \%$ & $4.92 \%$ & 0 \\
\hline
\end{tabular}

Kategorisasi berdasarkan mean hipotetik menunjukkan bahwa sebagian besar subjek penelitian memiliki optimisme dalam kategori tinggi, dukungan sosial dalam kategori sedang, serta integritas ego dalam kategori tinggi.

\section{Uji hipotesis}

Hasil analisis data dengan menggunakan analisis regresi berganda menunjukkan besarnya koefisien regresi $(F=47.12)$ dengan koefisien determinan $\left(R^{2}=.619\right)$; dan taraf signifikansi ( $p$ $=.000 ; p<.01)$. Berdasarkan hasil analisis tersebut dapat disimpulkan bahwa terdapat korelasi yang sangat signifikan antara optimisme dan dukungan sosial dengan integritas ego. Hasil uji hipotesis mayor dapat dilihat pada Tabel 3.

Hasil uji hipotesis minor yang pertama menunjukkan skor zero order ( $r=.785)$ dengan nilai signifikansi $(p=.000 ; p<.01)$ sehingga mengindikasikan bahwa ada hubungan yang siginifikan antara optimisme dengan integritas ego. Hasil uji hipotesis minor yang kedua menunjukkan skor zero order ( $r=.612$ ) dengan nilai signifikansi ( $p=.576 ; p>.01)$ sehingga mengindikasikan bahwa tidak ada hubungan antara dukungan sosial dengan integritas ego. Hasil uji hipotesis minor dapat dilihat pada Tabel 4.

\section{Tabel 3}

Hasil Uji Hipotesis Mayor

\begin{tabular}{lcc}
\hline \multicolumn{1}{c}{ Variabel } & $F$ & $p$ \\
\hline $\begin{array}{l}\text { Optimisme dan dukungan sosial terhadap integritas } \\
\text { ego }\end{array}$ & 47.12 & .000 \\
\hline
\end{tabular}

Catatan. Sumber: Data primer.

\section{Tabel 4}

Hasil Uji Hipotesis Minor

\begin{tabular}{lcc}
\hline \multicolumn{1}{c}{ Variabel } & $r$ & $p$ \\
\hline Optimisme*integritas ego & 0,785 & 0,000 \\
Dukungan sosial* integritas ego & 0,576 & 0,612 \\
\hline
\end{tabular}

Catatan. Sumber: Data primer.

\section{Pembahasan}

Hasil penelitian menunjukkan bahwa ada hubungan yang sangat signifikan antara optimisme dan dukungan sosial terhadap integritas ego. Selain itu, terdapat hubungan positif yang sangat signifikan antara optimisme dan integritas ego. Selanjutnya, diketahui pula bahwa peningkatan optimisme pada lansia akan 
diikuti dengan peningkatan integritas ego. Begitu pula sebaliknya, penurunan optimisme pada lansia dapat berdampak pada semakin rendahnya integritas ego. Penelitian menunjukkan bahwa optimisme adalah prediktor yang kuat pada kesejahteraan lanjut usia, serta memiliki kontribusi terhadap kesejahteraan lansia melalui ditunjukkannya dukungan sosial yang diperoleh lansia (Ferguson \& Goodwin, 2010).

Erikson (Erikson, 1998) menyatakan bahwa orang lanjut usia yang memiliki integritas ego yang tinggi akan merasa utuh dan puas dengan pencapaian yang telah diperoleh selama ini (Berk, 2017; Westerhof et al, 2015). Sebaliknya, perasaan putus asa akan muncul apabila orang lanjut usia merasa tidak yakin dalam mencapai integritas egonya. Integritas ego menurut James dan Zarett (2007) berkaitan dengan kemampuan seseorang untuk berdamai dengan diri sendiri dan menerima hidup sebagaimana adanya. Integritas ego berkaitan dengan (a) kesejahteraan psikologis yang lebih baik, (b) jiwa yang lebih optimis, (c) penerimaan diri yang lebih besar, (d) kepuasan pernikahan yang lebih tinggi, (e) hubungan yang lebih dekat dengan anak dewasa, (f) keterlibatan yang lebih besar dalam komunitas, dan (g) lebih bersedia untuk menerima bantuan dari orang lain saat membutuhkan.

Hasil penelitian yang dilakukan oleh Westerholf et al. (2015) menunjukkan bahwa faktor kepribadian dapat berpengaruh terhadap integritas ego pada lansia. Salah satu aspek kepribadian adalah optimisme. Selain itu, hasil penelitian terdahulu (Lee et al., 2019) menunjukkan bahwa para lansia yang memiliki kepribadian optimis akan memiliki usia harapan hidup yang panjang karena lebih mandiri, terbuka dengan berbagai pengalaman, serta memiliki kesehatan emosional lebih baik, sehingga sifat-sifat ini sangat penting bagi lansia untuk bisa bertahan sampai dengan usia 100 tahun (Berk, 2017).

Kemudian, saat dilakukan analisis terpisah, tampak bahwa dukungan sosial pada lansia ternyata tidak signifikan korelasinya. Argumentasi peneliti adalah dukungan sosial saat diberikan di usia lansia ternyata memiliki kompleksitas lebih tinggi dibandingkan usia di bawahnya (Jiang et al, 2018). Lansia cenderung akan melihat dukungan sosial dari sisi keuntungan maupun kerugian. Lansia dapat mempersepsi dukungan sosial sebagai bentuk beban sosial terhadap orang di sekitarnya. Hal ini berbeda dengan usia dewasa muda yang cenderung fokus pada sisi positif dari dukungan sosial. Selain itu, dukungan sosial yang dibutuhkan pada lansia cenderung pada dukungan emosional yang implisit. Padahal dalam pengukuran di penelitian ini melibatkan seluruh dimensi dalam dukungan sosial, baik dukungan instrumental, informasional, hingga emosional.

Apabila dukungan sosial diberikan pada lansia yang memiliki optimisme yang tinggi, maka dukungan sosial menjadi efektif untuk meningkatkan integritas ego pada lansia, namun 
apabila dukungan sosial tersebut diberikan pada lansia yang memiliki optimisme yang rendah, maka akan kurang berperan dalam meningkatkan integritas ego pada lansia. Hasil penelitian tersebut didukung oleh hasil riset yang menyatakan bahwa karakteristik kepribadian dari remaja hingga lansia cenderung stabil, walaupun memang ada sedikit perubahan (Harris et al., 2016). Hasil riset tersebut menguatkan bahwa aspek kepribadian merupakan salah satu faktor internal yang berpengaruh pada integritas ego pada lansia. Hal tersebut dapat terlihat dari hasil penelitian ini yang menunjukkan bahwa variabel yang berpengaruh terhadap integritas ego adalah optimisme dan bukan dukungan sosial, sehingga dukungan sosial tidak akan memberikan dampak yang positif bagi peningkatan integritas ego apabila tidak disertai dengan optimisme yang tinggi.

Hasil riset menunjukkan bahwa penyesuaian di usia lansia dibutuhkan, sebab di tahap ini telah terjadi banyak penurunan, mulai dari penurunan fungsi kesehatan, degenerasi fisik, memori, hingga perubahan peran sosial (Von Humboldt \& Leal, 2014). Hasil penelitian ini menunjukkan bahwa faktor internal (optimisme) lebih berperan daripada faktor eksternal (dukungan sosial) terhadap integritas ego pada lansia. Hal tersebut kemungkinan dapat terjadi karena subjek penelitian mayoritas berusia 60 sampai dengan 65 tahun, sehingga masih berada pada masa lansia awal. Kondisi tersebut menyebabkan belum terjadinya penurunan yang drastis dalam fungsi fisik, kognitif, penurunan fungsi dan potensi seksual, serta perubahan aspek psikososial sehingga mayoritas subjek penelitian belum terlalu membutuhkan dukungan sosial dari orang lain.

Subjek penelitian mayoritas berusia 60 sampai dengan 65 tahun, dan berdasarkan hasil wawancara dengan beberapa orang subjek penelitian, diperoleh informasi bahwa mayoritas subjek penelitian masih mandiri dalam melakukan aktivitas rawat diri. Selain itu, mayoritas subjek penelitian juga masih berusia produktif sehingga masih tetap terlibat dalam kegiatan sosial di masyarakat. Terdapat sebagian subjek penelitian yang meskipun sudah pensiun dari pekerjaannya dan lebih banyak menghabiskan waktu dengan tinggal di rumah, namun memiliki banyak aktivitas positif, misalnya menjadi pengurus kampung, menjadi takmir masjid, aktif dalam kegiatan sosial, dan aktif menjadi pengurus organisasi sosial bahkan menjadi pengurus kelompok lansia. Mayoritas lansia yang tetap aktif di masa tuanya tersebut merasa dirinya berharga karena tetap dapat memberikan kontribusinya pada masyarakat meskipun usianya sudah semakin menua.

\section{Simpulan}

Hasil penelitian menunjukkan bahwa optimisme dan dukungan sosial secara bersama-sama akan memengaruhi integritas ego pada lansia, optimisme juga memiliki 
pengaruh yang positif terhadap integritas ego, namun dukungan sosial tidak memberikan dampak apapun terhadap integritas ego apabila tidak disertai dengan optimisme yang tinggi.

\section{Saran}

Penelitian ini memiliki keterbatasanketerbatasan. Peneliti tidak memperoleh data demografis yang menunjukkan apakah lansia tinggal sendiri atau bersama orang lain. Hal ini kemungkinan dapat menjadi faktor yang berpengaruh terkait dengan sumber dukungan lansia. Jumlah responden dalam penelitian ini juga masih terbatas dan belum representatif dari sisi jenis kelamin maupun usia. Keterbatasanketerbatasan tersebut patut menjadi pertimbangan bagi peneliti selanjutnya. Saran peneliti adalah pentingnya penelitian berikutnya mempertimbangkan faktor demografi responden dan memperbanyak jumlah responden agar lebih representatif.

\section{Referensi}

Au, A., Lau, K., Koo, S., Cheung, G., Pan, P. C., \& Wong, M. K. (2009). The effect of social support on depressive symptom and life satisfaction in dementia caregivers in Hong Kong. Hong Kong Journal of Psychiatry, 19(2), 57-64.

Berk, L. E. (2012). Development through the lifespan. (Daryanto (ed.); 2nd ed.). Pustaka Pelajar.

Berk, L. E. (2017). Development through the lifespan (7th ed.). Pearson.

Carver, C. S., Scheier, M. F., \& Segerstrom, S. C. (2010). Optimism. Clinical Psychology Review, 30(7), 879-889. https://doi.org/ 10.1016/j.cpr.2010.01.006
Chang, P. J., Wray, L., \& Lin, Y. (2014). Social relationships, leisure activity, and health in older adults. Health Psychology, 33(6), 516-523. https://doi.org/https:// doi.org/10.1037/hea0000051

Dumitrache, C. G., Rubio, L., \& Cordón-Pozo, E. (2019). Successful aging in Spanish older adults: The role of psychosocial resources. International Psychogeriatrics, 31(2), 181-191. https:/ /doi.org/https://doi.org/10.1017/ S1041610218000388

Erikson, E. H. (1998). The life cycle completed: Extended version with new chapters on the ninth stage by Joan M. Erikson. Norton.

Feeney, B. C., \& Collins, N. L. (2015). Thriving through relationships. Pers Soc Psychol Rev., 19(2), 113-147. https://doi.org/ https://doi.org / 10.1016 / j.copsyc.2014.11.001

Ferguson, S. J., \& Goodwin, A. D. (2010). Optimism and well-being in older adults: The mediating role of social support and perceived control. The International Journal of Aging and Human Development, 71(1), 43-68. https:// doi.org/10.2190/ag.71.1.c

Haber, D. (2006). Life review: Implementation, theory, research, and therapy. The International Journal of Aging and Human Development, 63(2), 153-171. https://doi.org/10.2190/DA9G-RHK5N9JP-T6CC

Haley, M., Forrest-Lytle, J. J., \& Dadashazar, N. (2016). Late adulthood: Physical and cognitive development (Capuzzi \& M. D. Stauffer (eds.); Human grow). John Wiley \& Sons.

Harris, M. A., Brett, C. E., Johnson, W., \& Deary, I. J. (2016). Personality stability from age 14 to age 77 years. Psychology and Aging, 31(8), 862-874. https://doi.org/https:/ /doi.org/10.1037/pag0000133

James, J.B \& Zarrett, N. (2007). Ego integrity in the lives of older woman. Journal of Adult 
Development, 13(2), 61-75. https:// doi.org/10.1007/s10804-006-9003-2

James, P., Kim, E. S., Kubzansky, L. D., Zevon, E. S., Trudel-Fitzgerald, C., \& Grodstein, F. (2019). Optimism and Healthy Aging in Women. American Journal of Preventive Medicine, 56(1), 116-124. https:// doi.org/10.1016/j.amepre.2018.07.037

Jeong, H. S., \& Oh, H. S. (2015). Evaluating the comprehensive model of ego-integrity for senior patients in convalescent hospitals: Influence factors and outcome variables. International Journal of BioScience and Bio-Technology, 7(5), 317326. https://pdfs.semanticscholar.org/ $\begin{array}{lllll}2 & 6 & 5 & 5\end{array}$ 60f3257339dc2a3dafe01f5eb5f3c5f816a5.pdf

Jiang, L., Drolet, A., \& Kim, H. S. (2018). Age and social support seeking: Understanding the role of perceived social costs to others. Personality and Social Psychology Bulletin, 44(7), 1104-1116. https:// doi.org/https://doi.org/10.1177/ 0146167218760798

Kementrian Kesehatan RI. (2017). Analisis lansia di Indonesia. Pusat Data dan Informasi Kemenkes RI.

Khusaifan, S. J., \& El Keshky, M. E. S. (2017). Social support as a mediator variable of the relationship between depression and life satisfaction in a sample of Saudi caregivers of patients with Alzheimer's disease. International Psychogeriatrics, 29(2), 239-248. https://doi.org/ $10.1017 / \mathrm{S} 1041610216001824$

Lee, L. O., James, P., Zevon, E. S., Kim, E. S., TrudelFitzgerald, C., Spiro, A., Grodstein, F., \& Kubzansky, L. D. (2019). Optimism is associated with exceptional longevity in 2 epidemiologic cohorts of men and women. Proceedings of the National Academy of Sciences, 116(37), 18357 LP - 18362. https://doi.org/10.1073/ pnas. 1900712116

Lim, S. Y., \& Chang, S. O. (2018). Nursing home staff members' subjective frames of reference on residents' achievement of ego integrity: A Q-methodology study. Japan Journal of Nursing Science, 15(1), 17-30. https://doi.org/https://doi.org/ 10.1111/jjns.12166

Liu, H.-Y., \& Huang, L.-H. (2018). The relationship between family functioning and caregiving appraisal of dementia family caregivers: caregiving selfefficacy as a mediator. Aging \& Mental Health, 22(4), 558-567. https://doi.org/ 10.1080/13607863.2016.1269148

Menezes, S., \& Thomas, T. M. (2018). Development and experience of optimism and resilience in older adults. London Journal of Research in Humanities and Social Sciences, 18(3), 113. https://journalspress.com/ LJRHSS_Volume18/407_Developmentand-Experience-of-Optimism-andResilience-in-Older-Adults.pdf

Peck, R. C. (1956). Psychological developments in the second half of life. In J.E. Anderson (Ed), Psychological aspects of aging (pp. 42-53). American Psychological Association. https:/ /doi.org/10.1037/10032-005

Peck, R. C. (1968). Psychological development in the second half of life. University of Chcago Press.

Sarafino, E. P., \& Smith, T. W. (2011). Health psychology: Biopsychosocial interactions (7th ed.). John Wiley \& Sons.

Seligman, M. E. P. (2006). Learned optimism: How to change your mind and your life. Penguin Random House.

Tahren, S. F., \& Shaded, S. (2014). Reationship between ego integrity, despair, social support and health related quality of life. Pakistan Journal of Social and Clinical Psychology, 12(1), 12-33. https:// pdfs.semanticscholar.org/ $4 \mathrm{c} 4 \mathrm{e} /$ $4 \mathrm{~b} \mathrm{fbc}$ e $1677444 \mathrm{fde} 2385 \mathrm{f}$ 0 b 599 f 605351 e 0 e.pdf?_ga $=2.147277375 .982878159$. 1590393912-2010532096.1583108834

Torges, C. M., Stewart, A. J., \& Duncan, L. E. (2009). Appreciating life's complexities: 
Assessing narrative ego integrity in late midlife. Journal of Research in Personality, 43(1), 66-74. https:// doi.org/https://doi.org/10.1016/ j.jrp.2008.12.003

Unsar, S., Erol, O., \& Sut, N. (2016). Social support and health-related Quality of life among older adults. International Journal of Caring Sciences, 9(1), 249-256. https:// internationaljournalofcaringsciences.org/ docs/24_Unsar_original_9_1.pdf

Von Humboldt, S., \& Leal, I. (2014). Adjustment to aging in late adulthood: A systematic review. International Journal of Gerontology, 8(3), 108-113. h t tps://doi.org / 10.1016 / j.ijge.2014.03.003

Waite, L., \& Das, A. (2010). Families, social life, and well-being at older ages. Demography, 47(1), S87-S109. h t tps://doi.org/10.1353/ dem.2010.0009
Surat Keputusan Walikota Yogyakarta Nomor 450 Tahun 2019 Tentang Roadmap Kota Yogyakarta Menuju Kota Ramah Lanjut Usia, (2019) (testimony of Walikota Yogyakarta).

Westerhof, G. J., Bohlmeijer, E. T., \& McAdams, D. P. (2015). The relation of ego integrity and despair to personality traits and mental health. The Journals of Gerontology, 72(3), 400-407. https:// doi.org/https://doi.org/10.1093/ geronb/gbv062

Yeung, G. T.Y., \& Fung, H. H. (2007). Social support and life satisfaction among Hong Kong Chinese older adults: family first? European Journal of Ageing, 4(4), 219-227. https:// doi.org/10.1007/s10433-007-0065-1

Received 5 February 2020

Revised 24 April 2020

Accepted 30 May 2020 